\title{
Penentuan Faktor Daya Saing Industri Seafood Menggunakan Five Forces Analysis
}

\author{
Musmiana Mendong ${ }^{1}$, Rosmalina Hanafi ${ }^{1 *}$, Syarifuddin Parenreng ${ }^{1}$ \\ ${ }^{1}$ Departemen Teknik Industri, Fakultas Teknik, Universitas Hasanuddin \\ Jl. Poros Malino km. 6, Bontomarannu, Kabupaten Gowa, Sulawesi Selatan 92171 \\ Sulawesi Selatan 92171, Indonesia \\ *Email: rhanafi@unhas.ac.id
}

DOI: 10.25042/jpe.112019.08

\begin{abstract}
Abstrak
Industri seafood mengalami peningkatan ekspor secara perlahan setiap tahunnya yang berdampak pada tingginya nilai daya saing pada perusahaan. PT. Nirvana Niaga Sejahtera merupakan salah satu industri seafood yang bergerak dalam perdagangan ekspor komoditas tuna. Konsep analisis daya saing dan pemilihan supplier terbaik yang digunakan yaitu konsep Five Forces Analysis yang didasarkan pada indikator lima kekuatan seperti ancaman perusahaan yang akan masuk, pembeli, konsumen, produsen-produsen produk pengganti, analisis bagaimana kekuatan supplier dan metode AHP menggunakan software expert choice 11 menghasilkan supplier terbaik perusahaan. Hasil analisis model Five Forces Analysis menunjukkan bahwa ancaman investor pada perusahaan baru dan banyaknya perusahaan sejenis dapat mempengaruhi kekuatan daya tawar pembeli dan kualitas pemasok. Model pemilihan menggunakan AHP menghasilkan alternatif untuk supllier yang ditawarkan yaitu Supplier A (Toli-Toli) 0,385, Supplier B (Kendari) 0,322, Supplier C (Ternate) 0,279 .
\end{abstract}

\section{Abstract}

Determination of Seafood Industry Competitiveness Factors Using Five Forces Analysis. The seafood industry has experienced a gradual increase in exports each year which has an impact on the high value of competitiveness in companies. PT. Nirvana Niaga Sejahtera is a seafood industry engaged in the tuna commodity export trade. The concept of competitiveness analysis and the best supplier selection used is the Five Forces Analysis concept based on five strength indicators which are incoming company threats, buyers, consumers, substitute product manufacturers, analysis of supplier strengths and AHP methods use expert choice 11 software to produce the company's best supplier. The results of the Five Forces Analysis model show that investor threats to new companies and the number of similar companies can affect the bargaining power of buyers and the quality of suppliers. The selection model using AHP produces alternative for supplier that are Supplier A (Toli-Toli) 0.385, Supplier B (Kendari) 0.322, Supplier C (Ternate) 0.279.

Kata Kunci: AHP, competitiveness, five forces analysis, supplier selection

\section{Pendahuluan}

Seafood Indonesia meningkat secara perlahan dari tahun ke tahun sebesar $8,37 \%$ [1]. Peningkatan ekspor tersebut mengakibatkan nilai daya saing tinggi terhadap perusahaan sejenis. Faktor yang mempengaruhi daya saing adalah lokasi, harga, pelayanan, mutu dan kualitas serta promosi. PT Nirvana Niaga Sejahtera merupakan salah satu perusahaan industri seafood yang bergerak dalam perdagangan ekspor komoditas tuna dengan pengolahan Tuna Beku dan Fillet Tuna Saku yang dipotong sesuai dengan permintaan pasar dengan berat sekitar 180 350gr. Bahan baku tersebut diperoleh supplier dari beberapa daerah seperti Ternate, Toli-Toli, Kendari dan Sinjai.
Elemen yang sangat penting dimiliki oleh perusahaan untuk dapat meningkatkan rantai pasok yang baik dan mendapatkan kualitas mutu produk yang baik pula adalah pemilihan supplier. Pemilihan supplier dievaluasi dalam beberapa kriteria seperti biaya, pengiriman, kualitas dan lain-lain. Pada saat melakukan evaluasi dari beberapa kriteria sering terjadi trade off dimana supplier menawarkan produk dengan kualitas bagus tetapi pengirimannya tidak pasti. Pemilihan supplier pada Rubber Parts telah dilakukan dengan metode AHP dan menghasilkan 3 faktor kriteria yang dianggap penting perusahaan yaitu faktor produksi (48\%), kualitas (40\%), dan harga (12\%) [2]. Selain itu, penelitian ini menunjukkan supplier TRHI menghasilkan bobot terbesar $51,6 \%$ dibanding 
supplier lainnya seperti IKP $(24,8 \%)$ dan IRC $(23,6 \%)$. Oleh karena itu penentuan daya saing dalam memenuhi kebutuhan, pelayanan serta kualitas dan mutu bahan baku produk pada industri ekspor seafood salah satunya dengan memperhatikan supplier terbaik.

\section{Metode Penelitian}

Penelitian dilakukan di PT Nirvana Niaga Sejahtera yang berlokasi di Kawasan Industi Makassar (KIMA 6) selama bulan Juli 2019. Jenis pemilihan informan / responden yang dilakukan yaitu Snowball sampling atau Chain sampling yang pemilihan informan kedua berdasarkan informasi dari informan pertama, informan ketiga berdasarkan rekomendasi informan kedua dan seterusnya [3].

Variabel digunakan sebagai sinonim dari gagasan atau property yang sedang diteliti. Dalam AHP [4], terdapat 5 kriteria dan 12 subkriteria yang digunakan dalam penelitian ini. 5 kriteria tersebut antara lain Quality, Cost, Delivery, Flexibility dan Responsiveness

\subsection{Kriteria Kualitas (Quality)}

Kualitas merupakan faktor yang terdapat dalam suatu produk yang menyebabkan produk tersebut bernilai sesuai dengan maksud apa produk tersebut diproduksi. Adapun subkriteria dalam kriteria kualitas adalah kemampuan memberikan kualitas / kesegaran udang yang konsisten (Q1), kemampuan dalam memebrikan size dan mutu yang sesuai permintaan (Q2) dan penyediaan barang tanpa cacat (Q3).

\subsection{Kriteria Harga (Cost)}

Kriteria biaya sangat penting dalam operasi dan secara kasar dapat disamakan dengan efisiensi. Adapun subkriteria dalam kriteria harga adalah pemberian diskon untuk pembelian dalam jumlah besar $(\mathrm{C} 1)$ dan jumlah pembelian minimal (C2).

\subsection{Kriteria Pengiriman (Delivery)}

Kriteria dinilai sebagai salah satu faktor penting. Perusahaan dapat mengalami kerugian akibat kehilangan kesempatan menjual produk ke konsumen. Adapun subkriteria dalam kriteria pengiriman adalah ketepatan waktu pengiriman
(D1) dan ketepatan spesifikasi tuna yang dikirim terhadap order pembelian (D2).

\subsection{Kriteria Kemudahan (Flexibility)}

Jika supplier tidak bisa memberikan kemudahan/kecepatan dalam melayani permintaan bahan baku dari perusahaan. Maka hal ini akan berdampak pada stok bahan baku yang dimiliki perusahaan. Adapun subkriteria dalam kriteria flexibility adalah kemudahan penambahan/pengurangan jumlah pesanan (F1), kemudahan perubahan waktu pengiriman (F2) dan kemudahan untuk dihubungi (F3).

\subsection{Kriteria Tanggungjawab (Responsiveness)}

Supplier yang tidak konsisten dalam memberikan kualitas kepada perusahaan maka akan menjadikan produk perusahaan tersebut tidak berkualitas tinggi. Adapun subkriteria dalam kriteria Responsiveness adalah bisa merespon masalah dengan baik (R1) dan pemberian jaminan terhadap barang (R2).

Tabel 1. Five force analysis PT. NNS

\begin{tabular}{cl}
\hline Five Forces Analysis & \multicolumn{1}{c}{$\begin{array}{c}\text { Faktor yang } \\
\text { Mempengaruhi }\end{array}$} \\
\hline Pesaing Eksternal & Mexway \\
& Korea, Republic Of \\
& Australia \\
\hline Pesaing Internal & Pt. Wahyu Pradana \\
(Kawasan Industri & Pt. Kelola Mina Laut \\
Makassar) & Pt. Mitra Kartika Sejati \\
\hline \multirow{2}{*}{ Produk Pengganti } & Ikan Salmon \\
& Telur Ikan \\
& Ikan Pedang \\
& Belut \\
\hline Daya Tawar Pembeli & Konsumen Jepang \\
\hline \multirow{2}{*}{ Karu } & Kriteria Pemasok \\
& Kualitas Bahan Baku \\
& Harga \\
Daya Tawar Pemasok & Pengiriman \\
& Kemudahan \\
& Tanggung Jawab \\
\hline & Pt. Perikanan Nusantara \\
\hline
\end{tabular}




\section{Hasil dan Pembahasan}

\subsection{Faktor Daya Saing Five Forces Analysis}

Beberapa faktor yang mempengaruhi daya saing di PT NNS berdasarkan metode Porter [5].

\subsubsection{Persaingan Diantara Perusahaan Sejenis}

Norwegia merupakan negara pemasok komoditas salmon dan ikan torut dengan volume terbesar untuk produk HS0302. Kemudian diikuti Mexico dengan produk Tuna Sirip Biru, Indonesia dengan produk Big Eye Tuna, produk ekspor Unagi, Iwas hi, Aji, Saba dan ikan ikan air tawar yang khusus ditemukan di perairan asia timur dari Korea Selatan, produk Tuna sirip kuning yang didominasi dari Negara Indonesia dan Thailand, dan Tuna Sirip Biru Tenggara berasal dari Negara Australia. Khusus produksi big eye tuna dan ikan tuna sirip kuning Indonesia menjadi market leader sekaligus 3 besar pemasok ikan pedang (swordfish) di jepang. Sedangkan pada kawasan industri Makassar terdapat PT. Wahyu prada Pradana memiliki 5 cabang pabrik salah satunya terletak di Pabrik 3 terletak di Kima 4 dengan pengolahan dan pembekuan produk, ikan tuna, Gurita, Cumicumi dan Telur Ikan Terbang, PT Kelola Mina Laut yang telah memperkuat pasar ekspor dengan melakukan pengolahan ikan yang diekspor ke Thailand dan Vietnam. Disamping itu tahun 2018 PT Kelola Mina Laut juga membidik Negara Jepang dalam mengekspor Tuna fresh dan PT Mitra Kartika Sejati yang sudah beroperasi sejak tahun 1974 pada proses Marine Products Processing and Coldstorage.

\subsubsection{Masuknya Pendatang Baru}

PT Perikanan Nusantara merupakan salah satu badan usaha milik pemerintah yang berdiri pada tahun 1934 dan mewadahi 4 perusahaan seperti PT Tirta Raya Mina (Persero), PT Perikanan Samodra Besar (Persero), PT Perikani (Persero) dan PT Usaha Mina (Persero). Dan pada tahun 2018 PT Perinus telah melakukan perjanjian kerjasama dengan FTI Japan Co.Ltd dalam kesepakatan ekspor Tuna dengan target ekspor 240 ton.

\subsubsection{Produk Pengganti}

Masyarakat Jepang terbiasa mengkonsumsi makanan laut sebagai santapan sehari hari dalam kehidupannya dan terdapat beberapa produk yang memiliki tingkat permintaan yang tinggi seperti ikan jenis belut, ikan pedang dan salmon salar. Sehingga jika supply tuna mengalami penurunan masyarakat Jepang akan beralih ke produk pengganti tersebut.

\subsubsection{Daya Tawar Pembeli}

PT NNS adalah perusahaan yang tergolong masih baru berdiri pada tahun 2017 dan memiliki kurang lebih 200 karyawan. Saat ini, fokus pengolahan dan processing seafood PT NNS adalah ikan tuna dalam keadaan slice/potongan. Adapun negara yang menjadi fokus ekspor adalah negara Jepang dengan tingkat permintaan sekitar 200-300 ton sebulan.

\subsubsection{Daya Tawar Pemasok}

Keberadaan pemasok dalam menyediakan bahan baku produksi dan ekspor tuna merupakan salah satu faktor penting. Untuk mendapatkan bahan baku yang sesuai dengan permintaan dan kualitas yang tepat maka strategi yang perlu dilakukan perusahaan adalah menjalin hubungan yang baik dengan perusahaan dan mampu menilai supplier terbaik dengan mempertimbangan beberapa kriteria supplier seperti kualitas, harga, pengiriman, pelayanan dan tanggung jawab. Salah satu tujuan yang ingin dicapai dalam pemilihan supplier terbaik adalah mampu menjaga kekonsistenan pengadaan bahan baku dan jasa dengan biaya yang rendah

\subsection{Pemilihan Supplier Menggunakan Metode} AHP dan Expert Choice

Model ini menunjukkan tahapan pemilihan supplier menggunakan metode AHP dengan langkah-langkah sebagai berikut:

\section{a. Menyusun Hirarki}

Penyusunan hirarki ini dilakukan untuk identifikasi awal obje dengan menentukan tujuan yang ingin di capai serta kriteria- kriteria yang digunakan. 
Gambar 1 menunjukkan bahwa dalam pemilihan supplier menggunakan lima kriteria dan di setiap kriteria terdapat subkriteria yang menjabarkan definisi dari kriteria. Adapun alternatif supllier yang ditawarkan yaitu supplier A (Toli-Toli), B (Kendari) dan C (Ternate).

\section{b. Penentuan Prioritas}

Membuat matriks perbandingan berpasangan antar kriteria berdasarkan persepsi responden. Nilai numerik yang dikenakan untuk seluruh perbandingan diperoleh dari skala perbandingan Saaty.

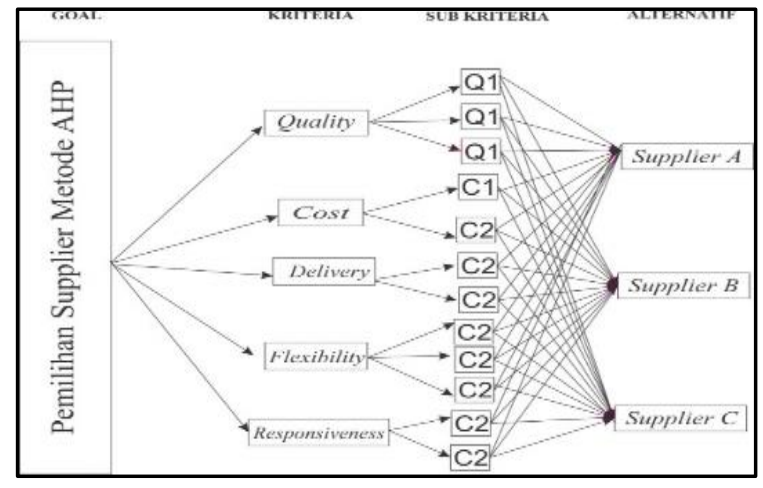

Gambar 1. Struktur hirarki pemilihan pemasok

Apabila suatu elemen A dinilai lebih penting (5) dibandingkan dengan elemen B, maka B lebih penting 1/5 dibandingkan elemen $\mathrm{A}$ dan apabila elemen A sama pentingnya dengan B maka masing masing bernilai $=1$ a. Uji Konsistensi Logis

Rumus dari indeks konsistensi (consistency index/CI) adalah

$$
C I=\frac{(\lambda m a k s-n)}{(n-1)}
$$

$$
\begin{aligned}
\lambda \text { maks }= & (2,0595 \times 0,439)+(4,7833 \times \\
& 0,270)+(19 \times 0,047)+(12,333 \times \\
& 0,091)+(7,666 \times 0,153) \\
& =5,3816 \\
C I= & \frac{(5.3816-5)}{(5-1)} \\
= & 0.095
\end{aligned}
$$

Suatu matriks perbandingan berpasangan dinyatakan konsisten apabila nilai consistency ratio $(\mathrm{CR}) \leq 10 \%$ dapat dihitung menggunakan rumus sebagai berikut:

\begin{tabular}{|c|c|c|c|c|c|c|c|c|c|c|c|c|c|c|c|c|c|c|}
\hline Kriteria & 9 & 8 & 7 & 6 & 5 & 4 & 3 & 2 & 1 & 2 & 3 & 4 & 5 & 6 & 7 & 8 & 9 & Kriteria \\
\hline Kualitas & & & & & & & & & & & $\mathrm{X}$ & & & & & & & Harga \\
\hline Kualitas & & & & & & & & & & & & & & & $X$ & & & Pengiriman \\
\hline Kualitas & & & & & & & & & & & & $X$ & & & & & & Kemudahan \\
\hline Kualitas & & & & & & & & & & & $X$ & & & & & & & Tanggung Jawab \\
\hline Harga & & & & & & & & & & & & & $\mathrm{X}$ & & & & & Pengiriman \\
\hline Harga & & & & & & & & & & & & $X$ & & & & & & Kemudahan \\
\hline Harga & & & & & & & & & & & $X$ & & & & & & & Tanggung Jawab \\
\hline Pengiriman & & & & $\mathrm{X}$ & & & & & & & & & & & & & & Kemudahan \\
\hline Pengiriman & & & & & $X$ & & & & & & & & & & & & & Tanggung Jawab \\
\hline Kemudahan & & & & & & & & & & & $\mathrm{X}$ & & & & & & & Tanggung Jawab \\
\hline
\end{tabular}

$$
C R=\frac{C I}{R I}
$$

dimana Indeks Random (RI) dengan nilai N (5) adalah 1,12

$$
\begin{aligned}
C R & =\frac{0.095}{1.12} \\
& =0.08
\end{aligned}
$$

Tabel 2. Perbandingan berpasangan antar kriteria responden 1 
Tabel 3. Nilai perbandingan berpasangan antar kriteria responden 1

\begin{tabular}{lccccc}
\hline Kriteria & Kualitas & Harga & Pengiriman & Kemudahan & Tanggungjawab \\
\hline Kualitas & 1 & 3 & 5 & 4 & 4 \\
Harga & 0,333 & 1 & 5 & 4 & 3 \\
Pengiriman & 0,2 & 0,2 & 1 & 0,1667 & 0,2 \\
Kemudahan & 0,25 & 0,25 & 6 & 1 & 0,2 \\
Tanggungjawab & 0,25 & 0,333 & 5 & 5 & 1 \\
\hline & 2,0333 & 4,783 & 22 & 14,1667 & 8,4 \\
\hline
\end{tabular}

Tabel 4. Nilai Eigenvector perbandingan berpasangan antar kriteria

\begin{tabular}{llllllll}
\hline Kriteria & Kualitas & Harga & Pengiriman & Kemudahan & Tanggungjawab & Total & Bobot \\
\hline Kualitas & 0,492 & 0,627 & 0,227 & 0,282 & 0,476 & 2,105 & 0,421 \\
Harga & 0,164 & 0,209 & 0,227 & 0,282 & 0,357 & 1,240 & 0,248 \\
Pengiriman & 0,098 & 0,042 & 0,045 & 0,012 & 0,024 & 0,221 & 0,044 \\
Kemudahan & 0,123 & 0,052 & 0,273 & 0,071 & 0,024 & 0,542 & 0,108 \\
Tanggungjawab & 0,123 & 0,070 & 0,227 & 0,353 & 0,119 & 0,892 & 0,178 \\
\hline & 1 & 1 & 1 & 1 & 1 & 5 & 1 \\
\hline
\end{tabular}

b. Model pengolahan AHP menggunakan Expert Choice

Menginput nilai pada Expert Choice setelah melakukan penyusunan hirarki dan penentuan prioritas.

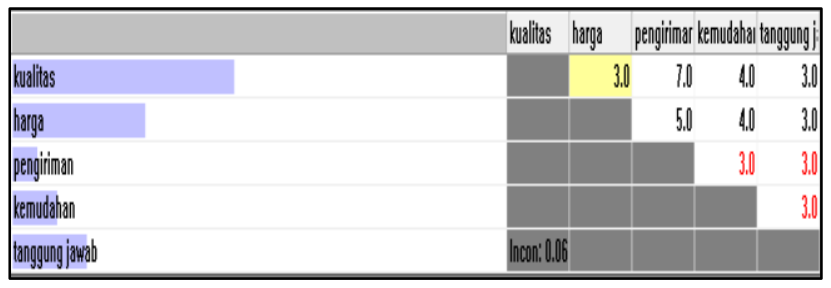

Gambar 2. Pairwise comparison antar kriteria (responden 1)

Perbandingan berpasangan yang diberikan responden memiliki nilai Incon/Consistency Ratio yang lebih kecil dari 0,1 sebagai batas maksimum nilai Incon/Consistency Ratio. Berdasarkan Gambar 2 diketahui Incon/Cinsistensy Ratio yaitu 0.06 dengan demikian hasil perhitungan cukup konsisten.

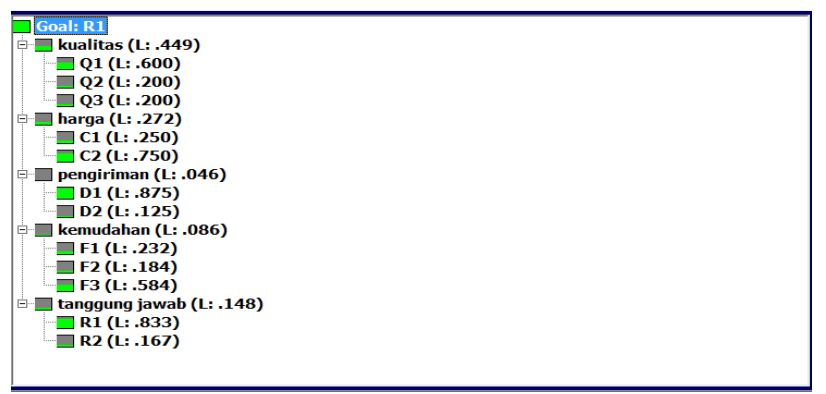

Gambar 3. Nilai Eigen vector (responden 1)
Nilai Eigen vector terhadap main kriteria dan subkriteria menghasilkan normalisasi matriks antar kriteria dan subkriteria yang akan menentukan bobot setiap kriteria dan subkriteria. Grafik tersebut menunjukkan kriteria kualitas mendapat nilai bobot 0.449 , kriteria harga 0,272 , kriteria pengiriman 0,046 , kriteria kemudahan 0,086 dan kriteria tanggung jawab 0,148. Sedangkan pada Gambar 5 menujukkan nilai bobot alternatif pada supplier A adalah 0.413, supplier B 0.359, supplier C 0.229.

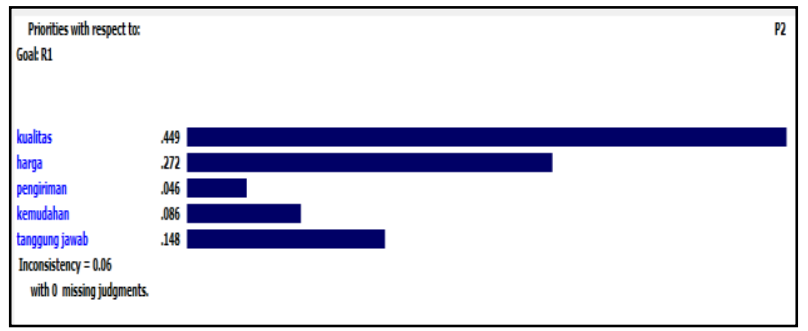

Gambar 4. Grafik prioritas kriteria responden 1

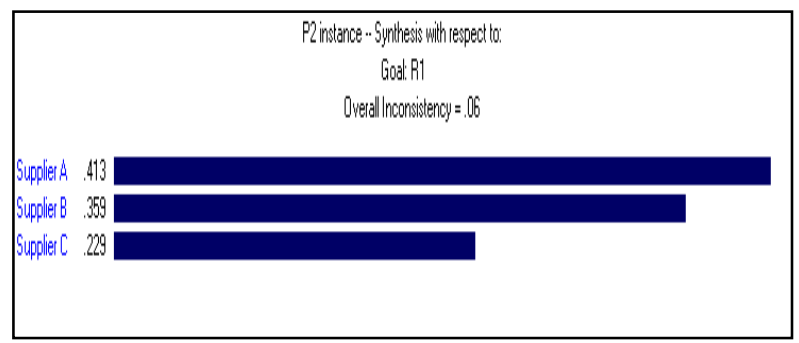

Gambar 5. Grafik prioritas goal (supplier) responden 1 


\section{Usulan dalam Pemilihan Supplier Metode AHP}

Penelitian ini menghasilkan lima matriks perbandingan berpasangan dalam persepsi responden yang telah melalui uji konsistensi yang dinyatakan konsisten, dengan consistency ratio < 0,1 .

Perhitungan matriks perbandingan berpasangan untuk keseluruhan kriteria menggunakan Ms. Excel 2010 dan Expert Choice 11 dihasilkan urutan yang mendapat posisi pertama berdasarkan perhitungan rata-rata dari keempat responden yang berwenang mengambil keputusan. Kriteria Tanggung jawab merupakan prioritas pertama dengan nilai bobot rata-rata 0.340 (0.338 Expert Choice), berikutnya adalah kriteria Kualitas dengan nilai bobot 0.307 (0.303 Expert Choice), Harga dengan nilai bobot 0.142 (0.285 Expert Choice), Kemudahan dengan nilai bobot 0.119 (0.237 Expert Choice) serta Pengiriman dengan nilai bobot $0.093 \quad(0.09$ Expert Choice).

Tabel 5. Hasil penentuan kriteria dan subkriteria

\begin{tabular}{|c|c|c|c|c|c|c|c|}
\hline \multirow{2}{*}{ No } & \multirow{2}{*}{$\begin{array}{l}\text { Kriteria } \\
\text { Perbandingan } \\
\text { Berpasangan }\end{array}$} & \multicolumn{4}{|c|}{ Pengambil Keputusan } & \multirow{2}{*}{$\begin{array}{l}\text { Rata } \\
\text {-Rata }\end{array}$} & \multirow[b]{2}{*}{ Prioritas } \\
\hline & & R1 & $\mathbf{R 2}$ & $\mathbf{R 3}$ & R4 & & \\
\hline \multicolumn{8}{|c|}{ Kriteria } \\
\hline \multirow[t]{5}{*}{1} & Kualitas & 0,439 & 0,420 & 0,122 & 0,246 & 0,307 & 2 \\
\hline & Harga & 0,270 & 0,117 & 0,063 & 0,116 & 0,142 & 3 \\
\hline & Pengiriman & 0,047 & 0,086 & 0,118 & 0,120 & 0,093 & 5 \\
\hline & Kemudahan & 0,091 & 0,147 & 0,052 & 0,187 & 0,119 & 4 \\
\hline & $\begin{array}{l}\text { Tanggung } \\
\text { Jawab }\end{array}$ & 0,153 & 0,230 & 0,645 & 0,331 & 0,340 & 1 \\
\hline \multicolumn{8}{|c|}{ Subkriteria } \\
\hline \multirow[t]{4}{*}{2} & Kualitas & & & & & & \\
\hline & Q1 & 0,6 & 0,6 & 0,333 & 0,690 & 0,556 & 1 \\
\hline & Q2 & 0,2 & 0,2 & 0,333 & 0,149 & 0,221 & 3 \\
\hline & Q3 & 0,2 & 0,2 & 0,333 & 0,161 & 0,223 & 2 \\
\hline \multirow[t]{3}{*}{3} & Harga & & & & & & \\
\hline & $\mathrm{C} 1$ & 0,25 & 0,25 & 0,875 & 0,25 & 0,406 & 2 \\
\hline & $\mathrm{C} 2$ & 0,75 & 0,75 & 0,125 & 0,75 & 0,594 & 1 \\
\hline \multirow[t]{3}{*}{4} & Pengiriman & & & & & & \\
\hline & D1 & 0,875 & 0,833 & 0,5 & 0,875 & 0,771 & 1 \\
\hline & D2 & 0,125 & 0,167 & 0,5 & 0,125 & 0,229 & 2 \\
\hline \multirow[t]{4}{*}{5} & Kemudahan & & & & & & \\
\hline & F1 & 0,234 & 0,525 & 0,2 & 0,389 & 0,337 & 2 \\
\hline & $\mathrm{F} 2$ & 0,187 & 0,142 & 0,6 & 0,100 & 0,257 & 3 \\
\hline & F3 & 0,579 & 0,334 & 0,2 & 0,511 & 0,406 & 1 \\
\hline \multirow[t]{3}{*}{6} & $\begin{array}{l}\text { Tanggung } \\
\text { Jawab }\end{array}$ & & & & & & \\
\hline & $\mathrm{R} 1$ & 0,833 & 0,5 & 0,5 & 0,833 & 0,667 & 1 \\
\hline & $\mathrm{R} 2$ & 0,167 & 0,5 & 0,5 & 0,167 & 0,333 & 2 \\
\hline
\end{tabular}

Tabel 6. Hasil prioritas alternatif supplier

\begin{tabular}{|c|c|c|c|c|c|c|}
\hline & \multicolumn{4}{|c|}{ Pengambil Keputusan } & \multirow[b]{2}{*}{$\begin{array}{c}\text { Rata - } \\
\text { Rata }\end{array}$} & \multirow[b]{2}{*}{ Prioritas } \\
\hline & $\begin{array}{c}\text { (R1) } \\
\text { Production } \\
\text { Manager }\end{array}$ & $\begin{array}{c}(\mathrm{R} 2) \\
\text { QC manager }\end{array}$ & $\begin{array}{c}(\mathrm{R} 3) \\
\text { Staff Produksi }\end{array}$ & $\begin{array}{c}(\mathbf{R} 4) \\
\text { Staff Produksi }\end{array}$ & & \\
\hline $\begin{array}{c}\text { Supplier } \\
\text { A } \\
\end{array}$ & $\begin{array}{c}4,606 \\
\text { (Prioritas 1) } \\
\end{array}$ & $\begin{array}{c}4,950 \\
(\text { Prioritas 1) } \\
\end{array}$ & $\begin{array}{c}4,083 \\
\text { (Prioritas 2) } \\
\end{array}$ & $\begin{array}{c}4,846 \\
(\text { Prioritas 1) } \\
\end{array}$ & 4,621 & 1 \\
\hline $\begin{array}{c}\text { Supplier } \\
B\end{array}$ & $\begin{array}{c}3,889 \\
\text { (Prioritas 2) }\end{array}$ & $\begin{array}{c}3,869 \\
\text { (Prioritas 3) }\end{array}$ & $\begin{array}{c}3,734 \\
\text { (Prioritas 3) }\end{array}$ & $\begin{array}{c}3,981 \\
\text { (Prioritas 2) }\end{array}$ & 3,868 & 2 \\
\hline $\begin{array}{c}\text { Supplier } \\
\text { C }\end{array}$ & $\begin{array}{c}2,838 \\
\text { (Prioritas 3) }\end{array}$ & $\begin{array}{c}3,182 \\
\text { (Prioritas 3) }\end{array}$ & $\begin{array}{c}4,184 \\
\text { (Prioritas 1) }\end{array}$ & $\begin{array}{c}3,173 \\
\text { (Prioritas 3) }\end{array}$ & 3,344 & 3 \\
\hline
\end{tabular}


Tabel 6 menujukkan bahwa supplier A memiliki keunggulan diantaranya adalah ketepatan spesifikasi ikan yang dikirim terhadap order pembelian, jumlah pembelian minimal, kemudahan perubahan yang diberikan apabila terjadi perubahan waktu, bisa merespon apabila ada masalah atau komplain dengan baik, bisa memberikan size dan mutu yang sesuai permintaan, pemberian diskon apabila dalam jumlah pembelian minimal. Supplier B menjadi prioritas kedua supplier terbaik yang berasal dari daerah Kendari menjadikan supplier B mengalami pengiriman yang cukup jauh dan penanganan rendah sehingga menyebabkan penurunan pada kualitas tuna. Akses pengiriman bahan baku hanya melalui darat yakni bus atau mobil truck dengan estimasi waktu perjalanan 25 jam hal ini tentu membuat waktu di perjalanan semakin lama. Berbeda dengan Supplier C yang berlokasi di daerah Ternate. Proses pengiriman barang bisa lebih cepat dibanding Supplier A dan B karena melalui jalur udara dengan estimasi perjalanan 4 jam dari Ternate ke Perusahaan. Namun, kekurangan bahan baku yang disupply supplier $\mathrm{C}$ memiliki size yang lebih kecil dibanding size yang di supply supplier A dan B.

\section{Kesimpulan}

Faktor yang mempengaruhi lima daya saing Porter menunjukkan bahwa pengaruh ancaman PT NNS sebagai perusahaan baru dalam industri seafood processing mendapatkan keunggulan kompetitif pada perusahaan sejenis baik dalam wilayah domestik maupun global. Sehingga, untuk tetap eksis perlu dilakukan penanganan serius untuk mendapatkan bahan baku yang bermutu dan berkualitas secara konsisten dengan memilih supplier terbaik dan supplier A daerah Toli-Toli merupakan supplier terbaik PT. NNS. Untuk hasil yang lebih baik dimungkinkan untuk menggunakan metode yang lain seperti Simple Additive Weighting (SAW) untuk mencari penjumlahan terbobot dari rating kinerja pada setiap alternatif. Penelitian selanjutnya dapat dilakukan untuk menganalisis upaya competitive strategy yang dilakukan untuk meningkatkan daya saing perusahaan.

\section{Referensi}

[1] ITPC, HS0302 Fish, Fresh or Chilled, Osaka, 2016.

[2] Rimantho, D., Fathurohman, B. Cahyadi, dan Sodikun, "Pemilihan Supplier Rubber Parts Dengan Metode Analytical Hierarchy Process Di PT.XYZ," Jurnal Rekayasa Sistem Industri vol. 6, no.3, pp. 93-103, 2017.

[3] Orcullo, Jr., N. A, Fundamentals of Strategic Management, Manila: RBSI'S Local Book Association Membership, 2008.

[4] Saaty, T.L, "Decision making with the analytic hierarchy process," Int. J. Services Sciences, vol.1, no.1, pp. 83-98, 2008.

[5] Dickson, G. W, "An Analysis of Vendor selection System and Decision, ” Journal of. Purchasing, vol. 2, no.1, pp. 5-20, 1966. 